\title{
Magnitude And Associated Factors of Intraoperative Nausea And Vomiting Among parturients who gave birth with Cesarean Section under Spinal Anesthesia At Hospitals in South Gondar Zone, Ethiopia
}

Basazinew Chekol Demilew ( $\square$ basechek06@gmail.com )

Debre Tabor University https://orcid.org/0000-0002-7815-1314

Fentaye Zewudu

Debre Tabor University

Dinberu Dinberu Eshetie

Debre Tabor University

Netsanet Temesgen Ayenew

Debre Tabor University

Eshetie Molla

Debre Tabor University

\section{Research}

Keywords: Spinal anesthesia, cesarean section, nausea/vomiting, parturients

Posted Date: April 9th, 2021

DOI: https://doi.org/10.21203/rs.3.rs-400885/v1

License: (c) (1) This work is licensed under a Creative Commons Attribution 4.0 International License. Read Full License 


\section{Abstract \\ Background}

Intraoperative nausea and vomiting is common intraoperative conditions by which parturient feel discomfort and disturbed after spinal anesthesia.

\section{Methods}

Hospital based cross-sectional study was conducted on mothers underwent cesarean section with spinal anesthesia. Descriptive analysis and chi square test were employed. Bivariable and multivariable logistic regression were used to measure the association of factors with the outcome variable intraoperative nausea and vomiting. A p-value of $\leq 0.05$ was used to decide statistical significance for multivariable logistic regression.

\section{Result}

A total of 246 parturients were participated in this study. The incidence of intraoperative nausea and vomiting was $40.2 \%$. According to multivariable logistic regression, age greater than 30 years (AOR, 6.26; $95 \% \mathrm{Cl}, 2.2-17.78$; p-value 0.001 ), primiparous ( $\mathrm{AOR}, 3.72 ; 95 \% \mathrm{Cl}, 1.35-10.24$; p-value, 0.011 ), having motion sickness (AOR, 7.1; 95\% Cl, 2.75-18.33; p-value 0.001), emergency cesarean sectin (AOR, 9.85; 95\% Cl, 3.19-30.38; p-value 0.001), oxygen suplimentation (AOR, $0.021 ; 95 \% \mathrm{Cl}, 0.005-0.08$; p-value $0.0001)$ and uterotonic agent (AOR, 2.99; $95 \% \mathrm{Cl} 1.24-7.22$; $p$-value 0.015$)$ had statistically significant association with intraoperative nausea and vomiting.

\section{Conclusion}

In our study, the overall incidence of intraoperative nausea and vomiting after spinal anesthesia was $40.2 \%$. Parturients with age greater than 30 years, having motion sickness, didn't got intraoperative supplemental oxygen, oxytocin used for uterotonic purpose, emergency surgery and primiparous were at increased risk intraoperative nausea and vomiting.

\section{Background}

Spinal anesthesia recently has gained popularity for cesarean section due to the change of attitude secondary to an increased awareness for the safety of regional block for both mother and newborns (14). The extremely small dose of local anesthetic used nearly eliminates the possibility of a systemic toxic reaction and will not cross the placenta to any appreciable degree compared with epidural anesthesia (3, $5)$. 
Nausea and vomiting are common in a wide variety of surgical operations. However, this problem arises even more often in cesarean operations under spinal anaesthesia. The incidence of IONV is as high as $80 \%$ (4) This condition is affected by factors that are particular to the patient, anesthesia, and surgery. Prediction of IONV is important for enabling appropriate and timely use of antiemetics $(6,7)$.

The stimulating factors of the vomiting mechanism can be stimulation of the vagal nerves, cerebral cortex, vestibular body, and the chemoreceptors trigger zone. The receptors of dopamine, serotonin, histamine, and muscarinic play a role in this process $(4,8)$.

Increased intragastric pressure due to gravid utres, hypotension, sretching the peritoneum (exteriorization of the uterus), excessive surgical manipulation and visceral stimulation, using opioids, using uterotonic agents, visceral type of pain, and the patient's mental status play a role and place the patient at high risk for IONV $(3,9,10)$. Hypotension associated with spinal,epidural, and spinal-epidural (combined) anaesthesia is a particularly important contributing factor for IONV $(4,7,11)$.

Pregnant women are already likely to suffer from nausea and vomiting throughout their pregnancy due to the reduced tone of the esophagogastric junction and an increased intraabdominal pressure .

Intraoperative nausea and vomiting (IONV) after spinal anesthesia in cesarean delivery are common occurrence and reported incidences are quite high. The well-being of patients may be severely compromised as $72 \%$ of patients are afraid of $\mathrm{NV}$ and $71 \%$ feel significant discomfort $(2,6)$. Nausea and vomiting with onset during the operation and persisting in the postoperative period cause reduced patient comfort, delayed discharge from the hospital, and an increase in cost (4).

To prevent IONV during cesarean section, blood pressure must be closely monitored, use of opioids must be kept to a minimum, the operative technique must be gentle with minimum displacement of the uterus (not exteriorising through an incision), and uterotonics and antibiotics must be administered in dilute and slow infusions $(10,12)$. Knowing magnitude and factors causing IONV helps urgent need of safety and treatment in the service of anesthesia to prevent its impact on surgery and patient satisfaction. Therefore this study aimed to determine the magnitude and associated factors of IONV during cesarean section under SA.

\section{Methods}

\section{Study area and period}

The study was conducted in three primary and one referral governmental hospitals found in South Gondar zone from February 01- April 30, 2020. Debre Tabor referral Hospital, Adiszemen primary hospital, Nefasmewucha primary hospital and Mekaneyesus primary hospital were the study area.

\section{Study Design}


A multicentre institutional based cross-sectional study was conducted to determine the magnitude and ssociated factors of intraoperative nausea and/or vomiting for parturients who gave birth with $\mathrm{C} / \mathrm{S}$ under spinal anesthesia.

\section{Population}

\section{Source Population}

All mothers undergoing Cesarean delivery under spinal anesthesia in south Gondar zone, Amhara, Ethiopia, 2020

\section{Study population}

All mothers undergoing Cesarean delivery under spinal anesthesia in south Gondar zone, Amhara, Ethiopia, 2020 during the study period, Debre Tabor, Ethiopia, 2020

\section{Eligible criteria}

The study was conducted on all mothers undergoing cesarean delivery under spinal anesthesia during the study period by excluding mothers having acute or chronic nausea and vomiting secondary to medical illness like PUD, gall bladder disease and bowel obstruction.

\section{Sample size and Sampling technique}

The total of 246 parturients who gave birth with caesarean section under spinal anesthesia were included in the study by non-probability consecutive sampling technique.

\section{Study Variables}

\section{Dependent Variables}

- Nausea and or vomiting (Yes/No)

\section{Independent Variables}

Socio demographic characteristics (Age, weight, parity, hx of smoking, hx of motion sickness or previous IONV), premedication (oxytocin, for augmentation, antiemetic, antibiotics), hemodynamic changes (BP, HR, SPo2), Drugs (Oxytocin, Ergometrine, Opioids), Anesthesia related factors (Baricity of LA, Dose of LA, 
Speed of injection, Level of block, and Position of the patient, adjuvants), Surgery related factors (manipulation, exteriorization of the uterus, Type of surgery)

\section{Data Collection Tool and Technique}

Data was collected through observation and face to face interviews by the trained data collectors. The data collection tool was prepared from different literatures which were done on related topic world-wide. The perioperative anesthetic and surgical managements was continuously observed by data collectors who were free from the intraoperative anesthesia management. Vital signs of each participantwas recorded during the surgery. Fluid used to preloading or co loading and anesthetic and surgical interventions during spinal anesthesia in operation theatre was documented.

\section{Data quality assurance}

To ensure the quality of data, training for the data collectors and the supervisor was given and pre-test was done. The supervisor was checked the data collectors and the completeness of the tool every day during data collection time.

\section{Data entry and analysis}

Data were coded and entered into Epi-data version 4.2 and was exported to SPSS version 23 for statistical analysis. Categorical socio-demographic data were summarized by frequencies and percentages of occurrence. The chi-square test was used to compare frequencies of respondents with categorical variables. Independent variables were analyzed using binary and multivariate logistic regression with the dependent variable. Variables with a $p$-value of $\leq 0.2$ form bivariable analysis were fitted to a multivariable logistic regression to check their association with dependent outcome. Adjusted Odds ratio with $95 \%$ confidence interval and the $p$-value of $\leq 0.05$ was considered to have significant association.

\section{Ethical consideration}

After proposal was reviewed by the department of anesthesia reviewing committee, ethical clearance and permission to conduct the research was obtained from the research and community service coordinator office of collage of health science, Debre Tabor University. Written informed consent was presented and obtained from each study participant according to the principles of Helsinki declaration.

\section{Operational Definition}


Hypotension -Systolic blood pressures or mean arterial pressure decreases by more than $20 \%$ from the pre-anesthetic value.

Nausea and vomiting: To say the parturient has nausea and vomiting during cesarean section under spinal anesthesia, a patient must have at least one episode of nausea and/or vomiting in the intraoperative period.

Amount of preloaded fluid: Amount of intravenous fluid given within 30 minutes before block placement.

Uterus exteriorization: the time when the uterus lifted out of the abdominal cavity during uterine repair.

\section{Result}

\section{Socio-demographic characteristics}

In this study a total of 246 parturients were participated. Majority $(63.4 \%)$ of the participants were aged $\leq$ 30 years and with $58.9 \%$ of them has BMI of between 18.5 and $24.9 \mathrm{~kg} / \mathrm{m}^{2}$. The mean age and BMI of the parturients were $29.57 \pm 5.5$ and $24.7 \pm 3.6$ respectivelly. Most of them $(59.8 \%)$ were from the urban area who are unemployed $(79.3 \%)$ in governmental work places (Table 1$)$. 
Table 1

Sociodemographic characterstics of participants who gave birth under spinal anesthesia in South Gondar zone governmental hospitals, 2021

\begin{tabular}{|c|c|c|c|}
\hline Variable & Categories & Frequency & Percentage \\
\hline \multirow[t]{2}{*}{ Age } & $>30$ & 90 & 36.6 \\
\hline & $\leq 30$ & 156 & 63.4 \\
\hline \multirow[t]{2}{*}{ BMI } & $18.5-24.9$ & 145 & 58.9 \\
\hline & $\geq 25$ & 101 & 41.1 \\
\hline \multirow[t]{2}{*}{ Educational level } & Illiterate & 69 & 28 \\
\hline & Literate & 177 & 72 \\
\hline \multirow[t]{2}{*}{ Marital status } & Married & 243 & 98.8 \\
\hline & Single & 3 & 1.2 \\
\hline \multirow[t]{2}{*}{ Residency } & Urban & 147 & 59.8 \\
\hline & Rural & 99 & 40.2 \\
\hline \multirow[t]{2}{*}{ Employment } & Employed & 51 & 20.7 \\
\hline & Unemployed & 195 & 79.3 \\
\hline \multirow[t]{2}{*}{ Smoking } & Yes & 3 & 1.2 \\
\hline & No & 243 & 98.8 \\
\hline \multirow[t]{2}{*}{ Alcohol } & Yes & 24 & 9.8 \\
\hline & No & 222 & 90.2 \\
\hline \multirow[t]{2}{*}{ Motion sickness } & Yes & 87 & 35.4 \\
\hline & No & 159 & 64.6 \\
\hline
\end{tabular}

\section{Clinical and parturition characteristics}

From the participants $98.8 \%$ and $65.9 \%$ were ASA II and Multiparous respectively. Forty eight (19.5\%) parturients had previous exposure for anesthesia and surgery from whom 27 (56.3\%) parturients had previous nausea and vomiting. From the participants $71.1 \%$ and $62.2 \%$ parturients were premedicated with antiemetics plazil and dexamethasone respectively. The baseline MAP of the parturients with mean and standard deviation was $89.8 \pm 8.05$ (Table 2). 
Table 2

Preoperative clinical and parturition characterstics of parturients who gave birth under spinal anesthesia in South Gondar zone governmental hospitals, 2021

\begin{tabular}{|c|c|c|c|}
\hline Variable & Category & Frequency & Percentage \\
\hline \multirow[t]{2}{*}{ ASA } & II & 243 & 98.8 \\
\hline & III & 3 & 1.2 \\
\hline \multirow[t]{2}{*}{ Parity } & Primiparous & 84 & 31.1 \\
\hline & Multiparous & 162 & 65.9 \\
\hline \multirow[t]{2}{*}{ Type of surgery } & Elective & 75 & 30.5 \\
\hline & Emergency & 171 & 69.5 \\
\hline \multirow[t]{2}{*}{ Previous anesthesia } & Yes & 48 & 19.5 \\
\hline & No & 198 & 80.5 \\
\hline \multirow[t]{2}{*}{ Plasil given } & Yes & 175 & 71.1 \\
\hline & No & 71 & 28.9 \\
\hline \multirow[t]{2}{*}{ Dexamethasone given } & Yes & 153 & 62.2 \\
\hline & No & 93 & 37.8 \\
\hline \multirow[t]{2}{*}{ NPO time } & $<6 \mathrm{hrs}$ & 105 & 42.7 \\
\hline & $>/=6 \mathrm{hrs}$ & 141 & 57.3 \\
\hline \multirow[t]{2}{*}{ Preload } & $</=500 \mathrm{ml}$ & 84 & 34.1 \\
\hline & $>500 \mathrm{ml}$ & 162 & 65.9 \\
\hline \multirow[t]{2}{*}{ Antibiotic given } & Ampiciline & 111 & 45.1 \\
\hline & Ceftriaxone & 135 & 54.9 \\
\hline \multirow[t]{2}{*}{ Preoperative oxytocin infusion } & Yes & 48 & 19.5 \\
\hline & No & 198 & 80.5 \\
\hline Baseline MAP & $89.8 \pm 8.05$ & & \\
\hline
\end{tabular}

\section{Intraoperative clinical conditions}

All parturients were given $0.5 \%$ bupivacaine for spinal anesthesia purpose with or without opioid adjuvants. Majority (63.4\%) of spinal anesthesia was done with greater than or equal to $2.5 \mathrm{ml}$ bupivacaine. From all, around 99 (40.2\%) of parturients complain intraoperative nausea and/or vomiting 
after spinal anesthesia. From the participants, around 39(15.9\%), 12(4.9\%) and 48(19.5\%) of parturients develop nausea only, vomiting only and both nausea and vomiting respectively. Around $91(37 \%)$ of participants was hypotensive at the 10th minute after spinal anesthesia administered with $\geq 20 \mathrm{mmhg}$ decresment from the baseline MAP (Table 3 and Fig. 1). 
Table 3

Intraoperative clinical and parturition conditions of mothers who gave birth under spinal anesthesia in South Gondar zone governmental hospitals, 2021

\begin{tabular}{|c|c|c|c|}
\hline Variable & Category & Frequency & Percentage \\
\hline \multirow[t]{2}{*}{ Intraoperative pain } & Yes & 15 & 6.1 \\
\hline & No & 231 & 93.9 \\
\hline \multirow[t]{2}{*}{ Volume of LA (0.5\% Bupivacaine) } & $<2.5 \mathrm{ml}$ & 90 & 36.6 \\
\hline & $>/=2.5 \mathrm{ml}$ & 156 & 63.4 \\
\hline \multirow[t]{2}{*}{ Spinal opioid adjuvant } & Yes & 63 & 25.6 \\
\hline & No & 183 & 74.4 \\
\hline \multirow[t]{2}{*}{ Level of block } & At \& Below T10 & 165 & 67.1 \\
\hline & Above T10 & 81 & 32.9 \\
\hline \multirow[t]{2}{*}{ Blood loss } & $</=1000 \mathrm{ml}$ & 225 & 91.5 \\
\hline & $>1000 \mathrm{ml}$ & 21 & 8.5 \\
\hline \multirow[t]{2}{*}{ Intraoperative $\mathrm{O}_{2}$ supplementation } & Yes & 150 & 61 \\
\hline & No & 96 & 39 \\
\hline \multirow[t]{2}{*}{ Hypotension ( $\geq 20 \%$ of baseline MAP } & Yes & 91 & 37 \\
\hline & No & 155 & 63 \\
\hline \multirow[t]{2}{*}{ Treatment of hypotension } & Yes & 21 & 8.5 \\
\hline & No & 225 & 91.5 \\
\hline \multirow[t]{2}{*}{ Treatment of bradycardia } & Yes & 27 & 11 \\
\hline & No & 219 & 89 \\
\hline \multirow[t]{2}{*}{ Uteretonic agent } & Oxytocin & 166 & 67.5 \\
\hline & Ergometrine alone, mixed & 80 & 32.5 \\
\hline \multirow[t]{2}{*}{ Left lateral tilt } & Yes & 102 & 41.5 \\
\hline & No & 144 & 58.5 \\
\hline Duration of surgery & $48.3 \pm 11.3$ & & \\
\hline \multirow[t]{2}{*}{ IONV } & Yes & 99 & 40.2 \\
\hline & No & 147 & 59.8 \\
\hline
\end{tabular}




\section{IONV and different independent factors}

Parturients who are less than 30years of age develops IONV more frequently than age greater than 30 years. From the illitrete participants around 36 (52.2\%) were suffered with IONV after spinal anesthesia. Forty six parturients complain IONV from parturients who were hypotensive at the 10th minute after spinal anesthesia (Table 4). 
Table 4

Incidence of IONV in related with different factors of participants who gave birth with caesarean section under spinal anesthesia ( $n=246$; with chi-square test), 2021.

\begin{tabular}{|c|c|c|c|c|}
\hline Variable & Categories & $\begin{array}{l}\text { Having IONV (99 } \\
(40.2 \%))\end{array}$ & $\begin{array}{l}\text { No IONV } \\
(147(59.8 \%))\end{array}$ & $\begin{array}{l}\mathrm{p}- \\
\text { value }\end{array}$ \\
\hline \multirow[t]{2}{*}{ Age } & $\leq 30$ & 69 (44.2\%) & $87(55.8 \%)$ & 0.11 \\
\hline & $>30$ & 30 (33.3\%) & $60(66.7 \%)$ & \\
\hline \multirow[t]{2}{*}{ BMI } & $18.5-24.9$ & $62(42.8 \%)$ & $83(57.2 \%)$ & 0.35 \\
\hline & $\geq 25$ & $37(36.6 \%)$ & $64(63.4 \%)$ & \\
\hline \multirow[t]{2}{*}{ Educational level } & Illiterate & $36(52.2 \%)$ & $33(47.8 \%)$ & 0.02 \\
\hline & Literate & $63(35.6 \%)$ & $114(64.4 \%)$ & \\
\hline \multirow[t]{2}{*}{ Marital status } & Married & $99(40.7 \%)$ & $144(59.3 \%)$ & 0.28 \\
\hline & Single & 0 & $3(100 \%)$ & \\
\hline \multirow[t]{2}{*}{ Residency } & Urban & $54(36.7 \%)$ & $93(63.3 \%)$ & 0.19 \\
\hline & Rural & $45(45.5 \%)$ & $54(54.5 \%)$ & \\
\hline \multirow[t]{2}{*}{ Employment } & Employed & $21(41.2 \%)$ & $30(58.8 \%)$ & 0.87 \\
\hline & Unemployed & $78(40.0 \%)$ & $117(60.0 \%)$ & \\
\hline \multirow[t]{2}{*}{ Parity } & Primipara & $24(28.6 \%)$ & $60(71.4 \%)$ & 0.009 \\
\hline & Multipara & $75(46.3 \%)$ & 87(53.7\%) & \\
\hline \multirow[t]{2}{*}{ Previous anesthesia } & Yes & $21(43.8 \%)$ & $27(56.2 \%)$ & 0.6 \\
\hline & No & $78(39.4 \%)$ & $129(60.6 \%)$ & \\
\hline \multirow[t]{2}{*}{ Motion sickness } & Yes & $48(55.2 \%)$ & $39(44.8 \%)$ & 0.001 \\
\hline & No & $51(32.1 \%)$ & $108(67.9 \%)$ & \\
\hline \multirow[t]{2}{*}{ Intraoperative pain } & Yes & $6(40 \%)$ & $9(60 \%)$ & 1 \\
\hline & No & $93(40.3 \%)$ & $138(59.7 \%)$ & \\
\hline \multirow[t]{2}{*}{ Type of surgery } & Emergency & $81(47.4)$ & $90(52.6)$ & 0.001 \\
\hline & Elective & 18(24) & $57(76)$ & \\
\hline \multirow[t]{2}{*}{ Dexamethasone } & Yes & $69(45.1)$ & $84(54.9)$ & 0.06 \\
\hline & No & $30(32.3)$ & $63(67.7)$ & \\
\hline
\end{tabular}

NPO: Null Per outh; BMI: Body Mass Index; MAP: Mean Arterial Presure;IONV: Intraoperative Nausea/Vomiting 


\begin{tabular}{|c|c|c|c|c|}
\hline Variable & Categories & $\begin{array}{l}\text { Having IONV (99 } \\
(40.2 \%))\end{array}$ & $\begin{array}{l}\text { No IONV } \\
(147(59.8 \%))\end{array}$ & $\begin{array}{l}\text { p- } \\
\text { value }\end{array}$ \\
\hline \multirow[t]{2}{*}{ NPO hours } & $<6 \mathrm{hrs}$ & $54(51.4)$ & $514(8.6)$ & 0.002 \\
\hline & $\geq 6 \mathrm{hrs}$ & 45(31.9) & $96(68.1)$ & \\
\hline \multirow[t]{2}{*}{ Opioid adjuvants } & Yes & $36(57.1)$ & $27(42.9)$ & 0.002 \\
\hline & No & 63(34.4) & $120(65.6)$ & \\
\hline \multirow[t]{2}{*}{ Supplemental $\mathrm{O}_{2}$} & Yes & $87(58)$ & $63(42)$ & 0.001 \\
\hline & No & $12(12.5)$ & $84(87.5)$ & \\
\hline \multirow{2}{*}{$\begin{array}{l}\geq 20 \mathrm{mmhg} \text { of baseline } \\
\text { MAP }\end{array}$} & Yes & $46(50.5)$ & $45(49.5)$ & 0.02 \\
\hline & No & $53(34.2)$ & $102(65.8)$ & \\
\hline
\end{tabular}

\section{Factor Analysis}

According to multivariable analysis, age $>30$, being primiparous, having motion sickness, caesarean section done in elective basis without oxygen suplimentation are significant factors for the development of IONV (Table 5). 
Table 5

Factors associated with the incidence of IONV for parturients underwent cesarean section with spinal anesthesia at the governmental hospitals in South Gondar zone (Bivariable and Multivariable logistic regression), 2021.

\begin{tabular}{|c|c|c|c|}
\hline Variables & Categories & COR, 95\% Cl \& P-value & AOR, 95\% Cl \& P-value \\
\hline \multirow[t]{2}{*}{ Age in year } & $>30$ & $1.59 ; 0.92-2.72 ; 0.11$ & $6.26 ; 2.2-17.78 ; 0.001$ \\
\hline & $\leq 30$ & 1 & \\
\hline \multirow[t]{2}{*}{ Parity } & Primiparous & $0.46 ; 0.26-0.82 ; 0.009$ & $3.72 ; 1.35-10.24 ; 0.011$ \\
\hline & Multiparous & 1 & \\
\hline \multirow[t]{2}{*}{ Motion sickness } & Yes & $2.61 ; 1.52-4.46 ; 0.001$ & $7.1 ; 2.75-18.33 ; 0.001$ \\
\hline & No & 1 & \\
\hline \multirow[t]{2}{*}{ Type of surgery } & Emergency & $0.35 ; 0.19-0.65 ; 0.001$ & $9.85 ; 3.19-30.38 ; 0.001$ \\
\hline & Elective & 1 & \\
\hline \multirow[t]{2}{*}{ O2 supplementation } & Yes & $12.89 ; 6.03-27.56 ; 0.0001$ & $0.021 ; 0.005-0.08 ; 0.0001$ \\
\hline & No & 1 & \\
\hline \multirow[t]{2}{*}{ Uterotonic agent } & Oxytocin & $0.511 ; 0.297-0.897 ; 0.018$ & $2.99 ; 1.24-7.22 ; 0.015$ \\
\hline & Ergometrine, mixed & 1 & \\
\hline
\end{tabular}

\section{Discussion}

Nausea and vomiting common in a wide variety of surgical operations. However,this problem arises even more often in cesarean operations under regional anesthesia. The incidence of IONV is as high as $80 \%$ in "high-risk" inpatients during the $24 \mathrm{~h}$ after operation(4). and is dependent on the anesthesia technique used, together with preventative and therapeutic measures employed by the anesthetis (5).

Intraoperative nausea and vomiting after spinal anesthesia in cesarean delivery are common occurrence high incidences. The well-being of patients may be severely compromised as $72 \%$ of patients are afraid of $\mathrm{NV}$ and $71 \%$ feel significant discomfort (2).

Our study was performed to assess the magnitude and possible risk factors which are associated with the intraoperative nausea vomiting during cesarean section under spinal anesthesia. This can help the clinical environment if we know the possible factors specially preventable factors and contribute to improve parturient's satisfaction in the perioperative period. Knowledge of independent IONV risk factors is crucial for the optimal use of antiemetic prophylaxis and multimodal management strategies (4).

The overall magnitude of IONV in this current study was $40.2 \%$ which is almost similar with the study done in University of Gondar on 373 parturients with the overall incidence of IONV 40.8\%. This similarity 
might be due to simllar characterstics in sociodemographic and clinical setups of the study areas (3). But the result of the present study is quite higher than the study done in Cape Towen on 258 parturients with the overall incidence of IONV was around $33 \%$. This small variation might be due to different in sociodemographic characterstics of the participants and the clinical setup difference. Also, the study was done only on elective type of surgery but the present study was done both on elective and emergency surgeries. The type of study can be the other possible justification for this variation by which the previous study was done under controlled approach with different protocols which limit the dose of medications and preload (13).

Another study showed that the incidence of IONV was $9.1 \%$ which is lower as compared to our study. Because the previous study was done by giving special concern and strict application for the prophylactic medications of nausea and vomiting and prevention of the possible risk factors of the complications. But in our study, $71 \%$ of parturients got antiemetic premedication (14).

Also a study done on 209 patients to predict the possible factors of IONV revealed that the overall incidence of IONV was 77 (36.8\%) patients experienced nausea during the caesarean operation and 19 (9.1\%) suffered from vomiting (10).

In our study, IONV was significantly associated with a maternal history of motion sickness (AOR = 7.1; $95 \% \mathrm{Cl}=2.75-18.33$ and $p$-value 0.001$)$. Parturients having motion sickness are around seven times more risky to develop IONV. The possible mechanisms can best be justified by a spectrum of susceptibility to vestibular-mediated stimulus, which lowers the threshold for nausea and vomiting with motion. Changes in position and transfer on a stretcher at the end of surgery can stimulate afferent neural pathways that project to the vestibular nuclei, leading to activation of the brain stem nuclei, triggering the somatic and gastrointestinal components of emesis $(10,14)$.

In our study mothers who underwent emergency cesarean section had significantly associated with IONV as compared with their elective counterparts $(A O R=9.85 ; 95 \% \mathrm{Cl}=3.19-30.38 ; \mathrm{p}$-value $=0.001)$. Emergeny based C/S were aproximetly 10 times more risky for IONV and this finding is in line with a study done by Abere et.al at Addis Ababa Ethiopia in determining the Magnitude and associated factors of nausea and vomiting during cesarean section under spinal anesthesia (15).

Most of the factors predisposing to IONV during cesarean section under spinal anesthesia which mostly are specific for CS. In our study parturients who took oxytocin for uerotonic purpose were significantly associated with IONV (AOR $=9.85 ; 95 \% \mathrm{Cl}=3.19-30.38$; $p$-value $=0.001)$. in agreement with this, the overall incidence of Nausea and vomiting was 29 and $9 \%$ respectively after the mothers had been given oxytocin infusion. IONV which mainly occurs as a result of hypotension produced by oxytocin administration (14).

In our study younger age of the parturient was associated with nausea and vomiting in the intraoperative period $(A O R=6.26 ; 95 \% \mathrm{Cl}=2.2-17.78 ; p=0.001)$. Parturients being greater than 30 years of age were six times more risky for development of IONV. This finding is supported by many literatures even though the 
nausea and vomiting they encountered was not merely in the intraoperative period and a group of patients were different (16-18).

Our study also revealed that an administration of supplemental oxygen during cesarean section was significantly associated with a decreased outcome of IONV. Most of the parturients who had intraoperative $100 \%$ supplemental oxygen with facemask did not develop nausea and vomiting. Other studies also reported that supplemental oxygen is effective to prevent nausea and vomiting (AOR = $0.021 ; 95 \% \mathrm{Cl}=0.005-0.08 ; \mathrm{p}$-value $=0.0001)$. Oxygen concentration greater than or equal to $80 \%$ can decrease nausea and vomiting it is found to be as effective or better than ondansetron $(19,20)$. But a systematic review and meta-analysis of controlled trials report revealed that an administration of a higher concentration of oxygen had a weak beneficial effect to prevent nausea and vomiting, but their study was among patients who underwent general anesthesia $(21,22)$.

According to our study primiparous parturients were at high risk of developing IONV with AOR of 3.72; $95 \% \mathrm{Cl}$ of $1.35-10.24$ and $p$-value- 0.01 . This might be due to psychological perspectives.

\section{Conclusion}

In our study, the overall incidence of intraoperative nausea and vomiting after spinal anesthesia was $40.2 \%$. for this incidence, age greater than 30 years old, having motion sickness, didn't got intraoperative suplimental oxygen, oxytocin used for uterotonic purpose, emergency surgery and primiparous were significant risk factors.

\section{Abbreviations}

AOR Adjusted Odds Ratio

BMI Body Mass Index

$\mathrm{Cl} \quad$ Confidence Interval

C/S Cesarean Section

COR Crudes Odds Ratio

IONV Intraoperative Nausea and Vomiting

MAP Mean Arterial Pressure

SA Spinal Anesthesia

SPSS Statistical Package for Social Science

\section{Declarations}


Ethics approval and consent to participate

In order to keep the ethical soundness of the research, an ethical approval and permission letter was obtained from the research and community service coordinator office of Debre Tabor University after the proposal was approved by department of anesthesia and the committee. Verbal and written consent was also secured before data collection from each participant.

Consent for publication

Not applicable.

Availability of data

All the necessary data will be provided for reasonable request

Funding

None

Competing interests

The authors declare that they have no competing interests.

Author Contributions

This work was carried out in collaboration among all authors. B. D contributed to the conception, the review and interpreted the literatures based on the level of evidence. F.Z, D.E, N.T and E.M contributed in reviewing preparation of the manuscript. All authors participate in preparation and critical review of the manuscripts. In addition, all authors read and approved the manuscript.

Corresponding author

Correspondence to Basazinew Chekol Demilew

Acknowledgment

We would like to acknowledge Debre Tabor University and Hospitals for their permission at where data was collected for this research. Also, we forward our gratitude for the data collectors and the participants of the study.

\section{References}

1. Deka B, Talukdar B, Laha A, Borah S. Effects of intravenous midazolam during spinal anaesthesia for caesarian section. International Journal of Basic and Clinical Pharmacology. 2016:754-7. 
2. Santos A, Datta S. Prophylactic use of droperidol for control of nausea and vomiting during spinal anesthesia for cesarean section. Obstetric Anesthesia Digest. 1984;4(3):89.

3. Ashagrie HE, Filatie TD, Melesse DY, Mustefa S. The incidence and factors associated with intraoperative nausea and vomiting during cesarean section under spinal anesthesia, July 2019. An institution based cross sectional study. International Journal of Surgery Open. 2020;26:49-54.

4. Simeneh Endalew EN, Gebremedhn EG, Gebreegzi AH, Gebreegzi AH, Kassahun HG, Kassa AA, et al. Effectiveness of Intravenous Metoclopramide Prophylaxis on the Reduction of Intraoperative and Early Postoperative Nausea and Vomiting after Emergency Caesarean Section under Spinal Anaesthesia. Journal of Anesthesia \& Clinical Research. 2018;09(03).

5. Sugo Y, Kubota M, Niwa H, Hirota K. Moderate rate of implementation of spinal anesthesia for cesarean section: does it improve neonatal well-being? A case-control study. Scientific reports. 2021;11(1):1-7.

6. Juhani TP, Hannele H. Complications during spinal anesthesia for cesarean delivery: a clinical report of one year's experience. Regional Anesthesia: The Journal of Neural Blockade in Obstetrics Surgery Pain Control. 1993;18(2):128-31.

7. Griffiths JD, Gyte GM, Paranjothy S, Brown HC, Broughton HK, Thomas J. Interventions for preventing nausea and vomiting in women undergoing regional anaesthesia for caesarean section. Cochrane Database of Systematic Reviews. 2012(9).

8. Becker DE. Nausea, vomiting, and hiccups: a review of mechanisms and treatment. Anesthesia progress. 2010;57(4):150-7.

9. Murphy MJ, Hooper VD, Sullivan E, Clifford T, Apfel CC. Identification of risk factors for postoperative nausea and vomiting in the perianesthesia adult patient. Journal of perianesthesia Nursing. 2006;21(6):377-84.

10. Semiz A, Akpak YK, Yilanlioglu NC, Babacan A, Gonen G, Cam Gonen C, et al. Prediction of intraoperative nausea and vomiting in caesarean delivery under regional anaesthesia. J Int Med Res. 2017;45(1):332-9.

11. Choi D, Kim J, Chung I. Comparison of combined spinal epidural anesthesia and epidural anesthesia for cesarean section. Acta anaesthesiologica Scandinavica. 2000;44(2):214-9.

12. Voigt M, Fröhlich CW, Hüttel C, Kranke P, Mennen J, Boessneck O, et al. Prophylaxis of intra-and postoperative nausea and vomiting in patients during cesarean section in spinal anesthesia. Medical science monitor: international medical journal of experimental clinical research. 2013;19:993.

13. Magni B, Dyer R, Van Dyk D, Van Nugteren J. Incidence of intraoperative nausea and vomiting during spinal anaesthesia for Caesarean section in two Cape Town state hospitals. Southern African Journal of Anaesthesia Analgesia. 2016;22(5):131-4.

14. Balki M, Carvalho J. Intraoperative nausea and vomiting during cesarean section under regional anesthesia. Int J Obstet Anesth. 2005;14(3):230-41.

15. Bantie AT, Woldeyohannes M, Ferede ZA, Regasa BA. Magnitude and associated factors of nausea and vomiting after ce-sarean section under spinal anesthesia in Gandhi memorial Hospi-tal, Addis 
Ababa, Ethiopia. A cross-sectional study. studies. 2020;3:7.

16. Borgeat A, Ekatodramis G, Schenker CA. Postoperative nausea and vomiting in regional anesthesia: a review. The Journal of the American Society of Anesthesiologists. 2003;98(2):530-47.

17. Dekkers GW, Broeren MA, Truijens SE, Kop WJ, Pop VJ. Hormonal and psychological factors in nausea and vomiting during pregnancy. Psychological medicine. 2020;50(2):229-36.

18. Guimarães GMN, Silva HBGd, Ashmawi HA. Risk factors for post-caesarean nausea and vomiting: a prospective prognostic study. Revista Brasileira de Anestesiologia. 2020;70(5):457-63.

19. Turan A, Apfel C, Kumpch M, Danzeisen O, Eberhart L, Forst $H$, et al. Does the efficacy of supplemental oxygen for the prevention of postoperative nausea and vomiting depend on the measured outcome, observational period or site of surgery? Anaesthesia. 2006;61(7):628-33.

20. Goll V, Akça O, Greif R, Freitag H, Arkiliç CF, Scheck T, et al. Ondansetron is no more effective than supplemental intraoperative oxygen for prevention of postoperative nausea and vomiting. Anesthesia Analgesia. 2001;92(1):112-7.

21. Hovaguimian F, Lysakowski C, Elia N, Tramèr MR. Effect of intraoperative high inspired oxygen fraction on surgical site infection, postoperative nausea and vomiting, and pulmonary function: systematic review and meta-analysis of randomized controlled trials. Anesthesiology. 2013;119(2):303-16.

22. Greif R, Laciny S, Rapf B, Hickle RS, Sessler DI. Supplemental oxygen reduces the incidence of postoperative nausea and vomiting. The Journal of the American Society of Anesthesiologists. 1999;91(5):1246-.

\section{Figures}

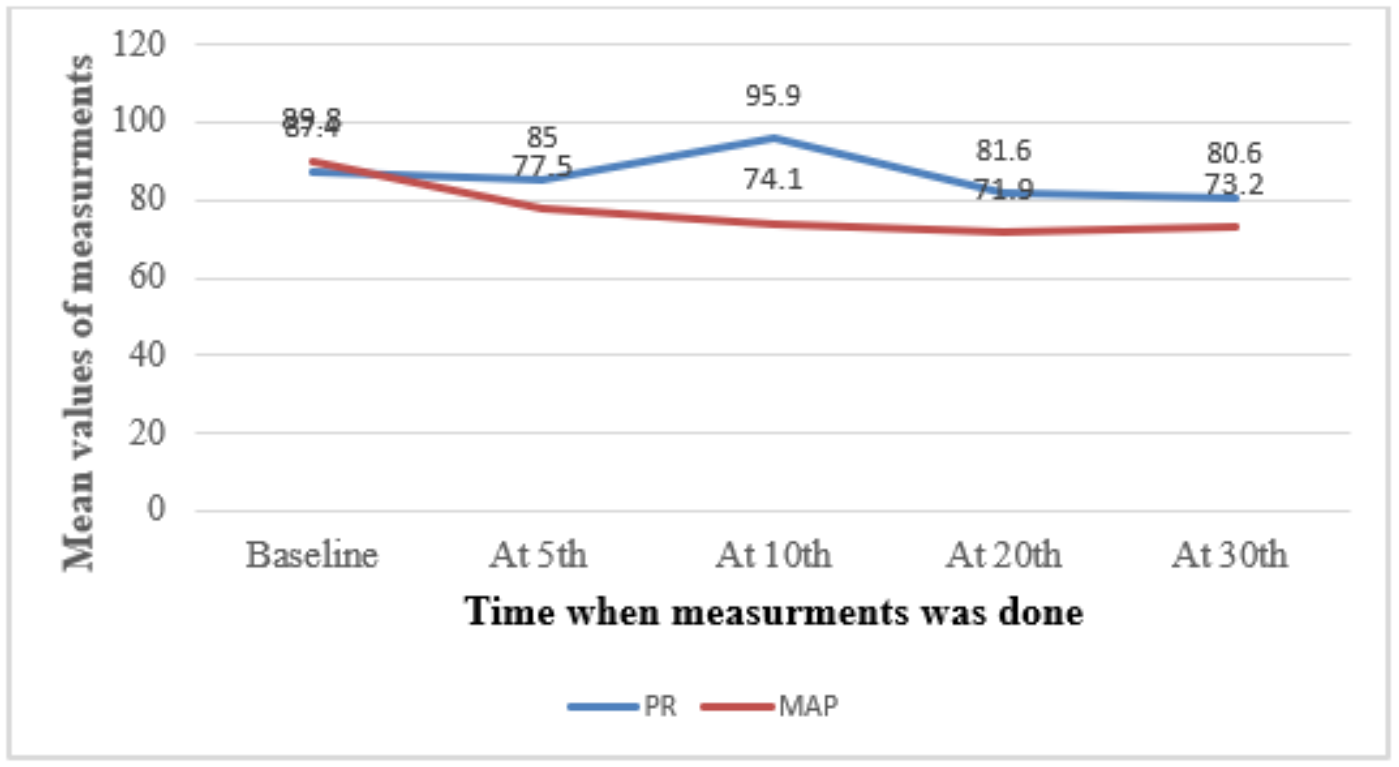

Figure 1 
line graph represent the vital sign trendes of parturients who gave birth with caesarean section under spinal anesthesia, 2021 